\title{
Exposure of hospitality workers to environmental tobacco smoke
}

\author{
M N Bates, J Fawcett, S Dickson, R Berezowski, N Garrett
}

Tobacco Control 2002;11:125-129

See end of article for authors' affiliations .....................

Correspondence to: Dr Michael Bates, School of Public Health, 140 Warren Hall, University of California, Berkeley, CA 94720, USA; m_bates@uclink.berkeley.edu

Received 8 August 2001 and revision requested 1 December 2001.

Accepted

6 February 2002

\begin{abstract}
Objective: To determine quantitatively the extent of exposure of hospitality workers to environmental tobacco smoke (ETS) exposure during the course of a work shift, and to relate these results to the customer smoking policy of the workplace.

Subjects: Three categories of non-smoking workers were recruited: (1) staff from hospitality premises (bars and restaurants) that permitted smoking by customers; (2) staff from smokefree hospitality premises; and (3) government employees in smokefree workplaces. All participants met with a member of the study team before they began work, and again at the end of their shift or work day. At each meeting, participants answered questions from a standardised questionnaire and supplied a saliva sample.

Main outcome measures: Saliva samples were analysed for cotinine. The difference between the first and second saliva sample cotinine concentrations indicated the degree of exposure to ETS over the course of the work shift.

Results: Hospitality workers in premises allowing smoking by customers had significantly greater increases in cotinine than workers in smokefree premises. Workers in hospitality premises with no restrictions on customer smoking were more highly exposed to ETS than workers in premises permitting smoking only in designated areas.

Conclusions: Overall, there was a clear association between within-shift cotinine concentration change and smoking policy. Workers in premises permitting customer smoking reported a higher prevalence of respiratory and irritation symptoms than workers in smokefree workplaces. Concentrations of salivary cotinine found in exposed workers in this study have been associated with substantial involuntary risks for cancer and heart disease.
\end{abstract}

$\mathrm{E}$ xposure of non-smokers to environmental tobacco smoke (ETS) has been associated with increases in risk for a number of diseases, including cancer, heart disease, and stroke. $^{12}$

The New Zealand Smokefree Environments Act 1990 protects workers from exposure to environmental tobacco smoke at work, usually by limiting smoking to certain designated areas. Special exemptions apply to premises, such as bars, that sell liquor. Smoking is permitted in any room or enclosed area set aside primarily for the consumption of liquor by patrons. Because of this exemption, bar workers, who may work long hours, day after day, in smoke filled environments, can experience particularly high levels of ETS exposure. Studies confirm that ETS in hospitality establishments, particularly bars, can reach substantial levels. ${ }^{3}$ However, ETS measurements do not necessarily provide a good basis for estimating actual exposure, since people do not usually remain in the same place for prolonged periods.

The purpose of this investigation was to quantify actual exposure of hospitality workers to ETS and how this exposure varied according to the customer smoking policy of the workplace. This was done by measuring changes in salivary cotinine concentrations over the period of a work shift. The intent of the study was to provide objective data on which policy and regulatory decisions about smoking in hospitality premises could be based.

Cotinine is a metabolite of nicotine, with a half life in the body of about 17 hours, compared to about two hours for nicotine. ${ }^{5}$ Cotinine can be detected in urine, blood, hair, and saliva. However, saliva can be more readily collected than blood or urine. Measuring hair cotinine concentrations was not appropriate because it would represent longer term expo- sures to tobacco smoke, from all sources, including those outside the work environment.

For non-smokers the difference in salivary cotinine concentrations between the samples collected at the beginning and the end of a work shift provides a measure of the extent of ETS exposure during that shift.

\section{METHODS}

\section{Recruitment of subjects}

Three groups of subjects were recruited, including two groups of hospitality workers: one group working in bars and restaurants that permitted smoking by customers, and a second group working in hospitality premises that did not permit customers to smoke (smokefree premises). Since there were few smokefree hospitality premises, a third group-employees in (smokefree) government ministries and departments-was recruited.

Three eligibility criteria were applied to all participants:

- participants could not have smoked for the previous six months

- participants could not be using any nicotine replacement therapy, such as nicotine patches or chewing gum. No enquiry was made about use of chewing tobacco or oral snuff. However, use of these products is very rare in New Zealand, their manufacture, commercial import and sale being prohibited by law.

- on the day of their participation in the study, participants needed to be working at least four hours; salivary cotinine concentrations plateau about four hours into a period of constant exposure. ${ }^{6}$

Multiple methods were used to attract hospitality worker participants, including letters from the employee union, 
Table 1 Distribution of cotinine concentrations measured in first saliva samples

\begin{tabular}{lllll}
\hline & \multicolumn{2}{l}{ Number of subjects } & \\
\cline { 2 - 3 } & \multicolumn{2}{l}{ Hospitality workers } & All workers in \\
\cline { 2 - 3 } $\begin{array}{l}\text { Cotinine concentration } \\
\text { (ng/g) }\end{array}$ & $\begin{array}{l}\text { Smoking } \\
\text { permitted }\end{array}$ & $\begin{array}{l}\text { Smokefree } \\
\text { workplace }\end{array}$ & $\begin{array}{l}\text { Government } \\
\text { employees }\end{array}$ & $\begin{array}{l}\text { Smokefree } \\
\text { workplaces }\end{array}$ \\
\hline Below detection limit* & $12(35 \%)$ & $6(60 \%)$ & $40(78 \%)$ & $46(75 \%)$ \\
0.2 to $<1$ & $3(9 \%)$ & $3(30 \%)$ & $9(18 \%)$ & $12(20 \%)$ \\
1 to $<2$ & $10(29 \%)$ & $1(10 \%)$ & $1(2 \%)$ & $2(3 \%)$ \\
2 to $<5$ & $6(18 \%)$ & 0 & 0 & 0 \\
$\geqslant 5 \dagger$ & $3(9 \%)$ & 0 & $1(2 \%)$ & $1(2 \%)$ \\
All subjects & $34(100 \%)$ & $10(100 \%)$ & $51(100 \%)$ & $61(100 \%)$ \\
\hline
\end{tabular}

*0.2 $\mathrm{ng} / \mathrm{g}$.

†Two hospitality workers (cotinine concentrations 9.7 and $23 \mathrm{ng} / \mathrm{g}$ ) and one government worker (15 ng/g)

were excluded from the subsequent statistical analysis (see text for justification).

newspaper advertising, distribution of pamphlets and posters, and direct canvassing of hospitality premises.

Wellington based government ministries and departments were asked if they would permit staff to participate in the study.

\section{Data and sample collection}

An interviewer met each hospitality worker participant at one of the study venues, immediately before and after their work shift. Before the participant began work, the first part of a two part questionnaire was interviewer administered, and a saliva sample collected. Questions were about hours worked in hospitality premises over the previous week, type of work, other recent ETS exposure, and whether the participant had recently experienced specific respiratory symptoms. A second (postshift) meeting took place at the end of the work shift when the second part of the questionnaire was administered and a second saliva sample collected. Similar procedures at the beginning and end of the workday were used for government employees with an appropriately adapted questionnaire to reflect the different nature of their work.

To maintain confidentiality no attempt was made to visit or take measurements in the workplaces of the hospitality worker participants. It was known that at least part of the industry was opposed to this study and we wished to avoid even the possibility that participants could be discriminated against by their employers.

Non-stimulated saliva samples (approximately $1 \mathrm{ml}$ ) were collected by asking the participant to spit into a plastic

Table 2 Demographic profiles of the study groups

\begin{tabular}{|c|c|c|c|}
\hline \multirow[b]{2}{*}{ Characteristic } & \multicolumn{2}{|c|}{ Hospitality workers } & \multirow[b]{2}{*}{$\begin{array}{l}\text { Government } \\
\text { employees }\end{array}$} \\
\hline & $\begin{array}{l}\text { Smoking } \\
\text { permitted }\end{array}$ & $\begin{array}{l}\text { Smokefree } \\
\text { workplaces }\end{array}$ & \\
\hline Total number & $32(100 \%)$ & $10(100 \%)$ & $50(100 \%)$ \\
\hline \multicolumn{4}{|l|}{ Sex } \\
\hline Males & $19(62 \%)$ & $3(30 \%)$ & $15(29 \%)$ \\
\hline Females & $13(38 \%)$ & $7(70 \%)$ & 35 (71\%) \\
\hline \multicolumn{4}{|l|}{ Age (years) } \\
\hline Range & $19.2-48.8$ & $18.1-46.6$ & $21.6-56.7$ \\
\hline Median & 23.8 & 24.2 & 31.9 \\
\hline \multicolumn{4}{|l|}{ Ethnicity* } \\
\hline European & $26(82 \%)$ & $8(80 \%)$ & 47 (94\%) \\
\hline Maori & $2(9 \%)$ & $1(10 \%)$ & $5(9 \%)$ \\
\hline Pacific People & $1(3 \%)$ & 0 & $1(2 \%)$ \\
\hline Asian & $1(6 \%)$ & $2(10 \%)$ & 0 \\
\hline Not answered & $2(6 \%)$ & 0 & 0 \\
\hline \multicolumn{4}{|l|}{ Smoking status } \\
\hline Never smoked & 19 (59\%) & $8(80 \%)$ & $39(76 \%)$ \\
\hline Ex-smoker & $13(41 \%)$ & $2(20 \%)$ & $11(24 \%)$ \\
\hline
\end{tabular}

* May not sum to column totals because participants could report more than one ethnicity.
Salivette tube (Sarstedt, Newton, North Carolina, USA). The standard Salivette tube contains a swab, intended to be chewed to release and absorb saliva. However, preliminary investigations found that cotinine was adsorbed onto the swab and not released during centrifugation. Therefore, the Salivette tubes were used without the swabs.

\section{Chemical analysis}

Analyses were conducted using a Shimadzu 10AVP high performance liquid chromatography (HPLC) system attached to a PE Sciex API 300 Triple-Quadrupole mass spectrometer equipped with a Turboionspray ion source. The HPLC column was a Phenomenex Luna $3 \mu \mathrm{m} \mathrm{Cl8(2),2.0 \times 50} \mathrm{mm,} \mathrm{with} \mathrm{a}$ $4.0 \times 2.0 \mathrm{~mm} \mathrm{C18}$ Phenomenex SecurityGuard cartridge. The mobile phase was a gradient of methanol and 10mM ammonium acetate.

Between 0.1-0.5 g (optimum $0.5 \mathrm{~g}$ ) of saliva was spiked with trideuterated cotinine (cotinine $\mathrm{D}_{3}$ ), made alkaline, and extracted with ethyl acetate. Glacial acetic acid $(30 \mu \mathrm{l})$ was added to the isolated ethyl acetate which was evaporated just to dryness. The dry residue in each tube was reconstituted to $100 \mu \mathrm{l}$ in aqueous $10 \mathrm{mM}$ ammonium acetate and methanol (50:50). The mass spectrometer was operated in the multiple ion monitoring mode. The positive ion transitions monitored were $\mathrm{m} / \mathrm{z} \quad 177 \rightarrow 80$ for cotinine and $180 \rightarrow 80$ for cotinine $\mathrm{D}_{3}$.

A nine point standard curve was created by spiking $0.5 \mathrm{ml}$ of deionised water with appropriate amounts of aqueous cotinine standards. As the lower end of the calibration was considered of greater significance, the calibration was weighted using a $1 / \chi^{2}$ weighting. The mean correlation coefficient was 0.99 .

The within-day reproducibility (six replicates) of the low standard $(0.4 \mathrm{ng} / \mathrm{g})$ had a coefficient of variation (CV) of 5.0\%, the high standard $(15 \mathrm{ng} / \mathrm{g})$ had a CV of $6.1 \%$. The between-day CV of the low standard was $11.7 \%$ (six days), the between-day CV of the high standard was $9.2 \%$ (five days). The detection limit was $0.2 \mathrm{ng}$ of cotinine per gram of saliva when $0.5 \mathrm{~g}$ of saliva was used.

\section{Statistical methods}

Participants were categorised according to the customer smoking policy of their workplace. Because of the predominance of cotinine values below the level of detection, non-parametric tests, including the Wilcoxon rank sum test, were used to investigate differences between median pre- and post-shift cotinine concentrations, for the different categories.

\section{RESULTS}

Ninety five subjects provided sufficient saliva samples for chemical analysis, of which 44 worked in 29 different restaurants and bars (hospitality workers), and 51 were government employees. All interviews took place during June to October 
Table 3 Changes in saliva cotinine concentrations between the first and second samples*

\begin{tabular}{|c|c|c|c|c|c|c|}
\hline \multirow{3}{*}{$\begin{array}{l}\text { Change in cotinine concentration } \\
\text { (second-first sample result) } \dagger\end{array}$} & \multirow[b]{2}{*}{$\begin{array}{l}\text { Government } \\
\text { employees }\end{array}$} & \multicolumn{3}{|c|}{ Hospitality workers } & \multirow{2}{*}{$\begin{array}{l}\text { All workers in } \\
\text { smokefree } \\
\text { workplaces }\end{array}$} & \multirow{2}{*}{$\begin{array}{l}\text { All workers in } \\
\text { workplaces that } \\
\text { allow smoking }\end{array}$} \\
\hline & & $\begin{array}{l}\text { Smokefree } \\
\text { workplaces }\end{array}$ & $\begin{array}{l}\text { Smoking only in } \\
\text { designated areas }\end{array}$ & $\begin{array}{l}\text { No smoking } \\
\text { restrictions }\end{array}$ & & \\
\hline & A & B & $\mathrm{C}$ & D & $E(=A+B)$ & $F(=C+D)$ \\
\hline Mean pre-shift (ng/g) & 0.12 & 0.37 & 1.12 & 1.60 & 0.16 & 1.30 \\
\hline Mean post-shift (ng/g) & 0.08 & 0.28 & 1.68 & 3.38 & 0.11 & 2.32 \\
\hline Number with decrease & $8(16 \%)$ & $3(30 \%)$ & $6(30 \%)$ & $1(8 \%)$ & $11(18 \%)$ & $7(22 \%)$ \\
\hline Number with no change & $36(72 \%)$ & $5(50 \%)$ & $6(30 \%)$ & $1(8 \%)$ & $41(68 \%)$ & $7(22 \%)$ \\
\hline Number with increase & $6(12 \%)$ & $2(20 \%)$ & $8(40 \%)$ & $10(83 \%)$ & $8(13 \%)$ & $18(56 \%)$ \\
\hline Median (ng/g) $\ddagger$ & 0.15 & 0.1 & 1.6 & 1.7 & 0.14 & 1.65 \\
\hline Mean $(\mathrm{ng} / \mathrm{g}) \ddagger$ & 0.16 & 0.1 & 1.8 & 2.2 & 0.15 & 1.95 \\
\hline Range $(\mathrm{ng} / \mathrm{g}) \ddagger$ & $0.08-0.3$ & $0.05-0.13$ & $0.1-3.6$ & $0.2-7$ & $0.05-0.3$ & $0.1-7.0$ \\
\hline Overall mean cotinine increase $(\mathrm{ng} / \mathrm{g}) \S$ & 0.02 & 0.02 & 0.7 & 1.8 & 0.02 & 1.11 \\
\hline Total number in group & $50(100 \%)$ & $10(100 \%)$ & $20(100 \%)$ & $12(100 \%)$ & $60(100 \%)$ & $32(100 \%)$ \\
\hline
\end{tabular}

*The average times between samples were 7.6 and 8.4 hours for hospitality workers in smoking and non-smoking premises, respectively, and 7.2 hours for government employees. †Setting results less than the limit of detecti
†Ubjects with cotinine increases only.

$\S$ Subjects with a decrease in cotinine concentration taken as having no change. Assumes that a decrease is the result of clearance of work unrelated ETS exposure.

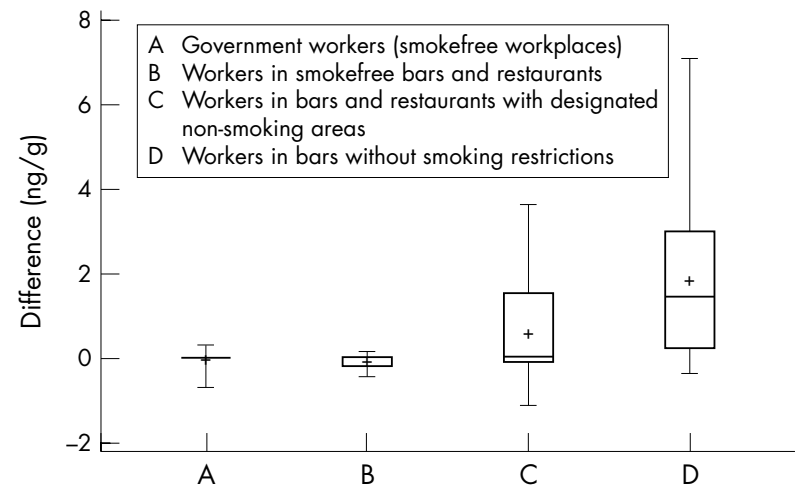

Figure 1 Changes in salivary cotinine concentration for government and hospitality workers (by category of workplace customer smoking policy). Whiskers show the extreme values; boxes show the 25 th and 75 th centiles and median; + indicates mean value.

2000. Pre-shift saliva sample cotinine results were used to confirm the eligibility of participants. Table 1 shows the concentrations of cotinine measured in the first (pre-shift) saliva samples.

A value of $7.0 \mathrm{ng} / \mathrm{g}$ was the criterion used to identify and exclude results for possible smokers and nicotine replacement therapy users from the statistical analysis. ${ }^{5}$ On that basis, two hospitality workers and one government employee were excluded. The highest pre-shift salivary cotinine concentration among those who were included in the statistical analysis was $5.1 \mathrm{ng} / \mathrm{g}$, in a person who worked in a bar where smoking was permitted.

Forty two hospitality workers and 50 government employees remained in the study and were included in the subsequent statistical analyses.

The demographic composition and smoking history of the study groups is shown in table 2. The workplaces where smoking was permitted fell into two categories of customer smoking policy: (1) smoking permitted only in designated area(s); and (2) smoking allowed anywhere in the premises.

Table 3 summarises the data on changes in cotinine concentrations between the pre-shift and post-shift samples, for study subjects (columns A-D). Figure 1 also shows the distributions of cotinine changes.

Two key trends are apparent in the data shown in table 3. The less restrictive the policy on customer smoking (or smok- ing at work): ( 1 ) the higher the proportion of subjects in the group with an increase in salivary cotinine concentration; and (2) the greater the magnitude of the cotinine concentration increases in the subsets of subjects who show increases.

The two unexposed groups in table 3 (columns A and B) are consistent in having identical very low mean increases in salivary cotinine concentration $(0.02 \mathrm{ng} / \mathrm{g})$ by comparison with the two exposed groups ( 0.7 and $1.8 \mathrm{ng} / \mathrm{g}$ ) (columns C and D).

The data in table 3 were statistically analysed in both categorical and continuous formats. For the categorical analysis of the data in table 3, subjects were combined according to whether they did or did not have an increase in cotinine concentration between the two samples. Also, study participants working in non-smoking hospitality premises were combined with the government employee group. Since both groups were working in non-smoking workplaces, pre- to post-shift cotinine variation in both groups should be representative of such variation in non-smoking populations exposed to ETS outside of the workplace.

The resulting distribution of data is shown in table 4 .

A test for linear trend of proportions on the first three columns of data in table 4 gave a p value of $<0.00001\left(\chi^{2}=25.2\right.$, $\mathrm{df}=1)$, indicating that the permissiveness of the smoking policy of a workplace is directly associated with the likelihood of an increase in salivary cotinine concentration while at work

Treating the data as continuous, a Wilcoxon rank sum test of equality of medians was used, comparing the pre- to postshift cotinine difference in all hospitality workers working in premises permitting smoking $(\mathrm{n}=32)$ with the difference in all workers in hospitality premises not permitting smoking $(\mathrm{n}=10)$. Reductions in cotinine were retained as such in the data. This comparison gave a p value of 0.05 for the difference between the two groups. However, after combining all workers in smokefree workplaces $(n=60)$ and comparing them against the group of those who worked in premises where smoking was permitted, the $p$ value was 0.002 . This confirms that working in hospitality premises where any smoking is permitted is very significantly associated with higher concentrations of cotinine in saliva (and hence higher exposures to ETS over the course of a work shift).

Using the Wilcoxon test the changes in cotinine concentrations for workers in hospitality premises with no customer smoking restrictions were compared with workers in premises with designated non-smoking areas. The difference in medians $(p=0.03)$ indicates that the difference in cotinine changes between the two groups of exposed workers (table 3 ) is not likely to be caused by chance. 
Table 4 Change in cotinine after combining categories

\begin{tabular}{|c|c|c|c|c|}
\hline \multirow[b]{2}{*}{ Cotinine change } & \multicolumn{3}{|c|}{$\begin{array}{l}\text { Workplace smoking policy (number and proportion of } \\
\text { subjects) }\end{array}$} & \multirow[b]{2}{*}{ Total } \\
\hline & $\begin{array}{l}\text { No smoking } \\
\text { restrictions }\end{array}$ & $\begin{array}{l}\text { Smoking in restricted } \\
\text { areas }\end{array}$ & Smokefree† & \\
\hline Increase & $10(83 \%)$ & $8(40 \%)$ & $8(13 \%)$ & $26(28 \%)$ \\
\hline No increase* & $2(17 \%)$ & $12(60 \%)$ & $52(87 \%)$ & $66(72 \%)$ \\
\hline Total & $12(100 \%)$ & $20(100 \%)$ & $60(100 \%)$ & $92(100 \%)$ \\
\hline
\end{tabular}

Study participants were asked a number of questions about respiratory and irritation symptoms experienced in the previous four weeks, as well as questions on asthma. Responses to these questions are summarised in table 5, along with prevalence ratios and associated confidence intervals. Prevalence ratios were calculated after combining responses from both groups of workers in premises where smoking was not permitted, and using this as the baseline for comparison with the hospitality workers in premises where smoking was permitted.

The prevalence ratios in table 5 show that there is a tendency for workers in premises permitting customer smoking to report a higher prevalence of respiratory and irritation symptoms than workers in smokefree workplaces. Asthma diagnosed by a doctor and use of asthma medication were less common in workers in bars and restaurants where smoking was permitted.

\section{DISCUSSION}

This is the first New Zealand study that has examined exposure to ETS specifically in the hospitality workplace. Also, as far as we are aware, it is the first study anywhere that has examined differences in pre- and post-shift salivary cotinine concentration changes in hospitality workers in relation to workplace smoking policies. One other New Zealand study measured nicotine concentrations in the hair of hospitality workers and found differences according to smoking policy of the premises. ${ }^{7}$ However, hair nicotine concentrations represent the accumulation of exposures from a variety of workplace and non-workplace sources over a longer period of time, and will be less specific to workplace ETS exposures than the salivary cotinine concentrations used in this study.
For practical reasons, the study used volunteers rather than randomly selected participants. However, we see no reason why our results would have been different in a randomly selected group. The results of this investigation show convincingly that workers in hospitality premises that permit customer smoking have higher salivary cotinine concentrations at the end of their shift than at the beginning of their shift.

This result is consistent with the results of other studies using a variety of methods to assess ETS exposure. ${ }^{8-11}$ Using measurements of ambient indoor air concentrations of carbon monoxide, nicotine, and respirable suspended particles, Siegel $^{12}$ concluded that restaurant and bar workers were exposed to ETS at a concentration between 1.5-4.4 times greater than that received by someone living with a smoker.

The results of this study confirm that second hand smoke exposure of staff is greatest in premises where there are no restrictions on where customers may smoke. Workers in these premises appeared to receive about three times the exposure of workers in premises where customers were permitted to smoke, but only in designated areas. However, even in premises where there were some limitations on smoking, increases in cotinine of study participants were still much greater than the increases for workers in smokefree premises (table 3 ). This result was also consistent with the results of other studies, which have shown the allocation of specific areas for non-smoking customers provides only partial protection from exposure to ETS. ${ }^{413}$ Studies suggest that ETS exposure can vary and according to the type of workwaiting, bar work, and kitchen staff work-being undertaken. ${ }^{814} 15$ The range of within-group cotinine changes in the hospitality worker subjects in this study was wide. This

Table 5 Responses to questions about symptoms and asthma-proportion reporting symptom, by category of workplace smoking policy

\begin{tabular}{|c|c|c|c|c|c|c|c|c|}
\hline \multirow[b]{4}{*}{ Question* } & \multirow[b]{2}{*}{$\begin{array}{l}\text { Government } \\
\text { workers }\end{array}$} & \multicolumn{3}{|c|}{ Hospitality workers } & \multirow{2}{*}{$\begin{array}{l}\text { All workers in } \\
\text { smokefree } \\
\text { workplaces }\end{array}$} & \multirow{2}{*}{$\begin{array}{l}\text { All workers in } \\
\text { workplaces that } \\
\text { allow smoking }\end{array}$} & \multirow[b]{2}{*}{$\begin{array}{l}\text { Prevalence } \\
\text { ratio† }\end{array}$} & \multirow[b]{4}{*}{$95 \% \mathrm{Cl}$} \\
\hline & & $\begin{array}{l}\text { Smokefree } \\
\text { workplaces }\end{array}$ & $\begin{array}{l}\text { Smoking only in } \\
\text { designated areas }\end{array}$ & $\begin{array}{l}\text { No smoking } \\
\text { restrictions }\end{array}$ & & & & \\
\hline & A & B & C & D & $E(=A+B)$ & $F(=C+D)$ & $\mathrm{F} / \mathrm{E}$ & \\
\hline & $\mathrm{n}=50$ & $n=10$ & $\mathrm{n}=20$ & $\mathrm{n}=32$ & $n=60$ & $n=32$ & & \\
\hline Wheezing in chest & 0.24 & 0.2 & 0.3 & 0.25 & 0.23 & 0.28 & 1.21 & 0.59 to 2.47 \\
\hline Short of breath & 0.14 & 0 & 0.25 & 0.33 & 0.12 & 0.28 & 2.41 & 0.99 to 5.87 \\
\hline Cough in morning & 0.2 & 0 & 0.15 & 0.33 & 0.17 & 0.22 & 1.31 & 0.55 to 3.12 \\
\hline Frequently cough & 0.2 & 0 & 0.4 & 0.17 & 0.17 & 0.31 & 1.88 & 0.87 to 4.03 \\
\hline Frequent phlegm & 0.18 & 0 & 0.35 & 0.42 & 0.15 & 0.38 & 2.53 & 1.18 to 5.29 \\
\hline Eye irritation & 0.42 & 0 & 0.25 & 0.5 & 0.35 & 0.34 & 0.98 & 0.54 to 1.77 \\
\hline Running nose & 0.44 & 0.5 & 0.6 & 0.5 & 0.45 & 0.56 & 1.25 & 0.83 to 1.89 \\
\hline Sore throat & 0.32 & 0.2 & 0.3 & 0.33 & 0.30 & 0.31 & 1.04 & 0.55 to 1.98 \\
\hline Asthma diagnosed & 0.34 & 0.2 & 0.25 & 0.25 & 0.32 & 0.25 & 0.79 & 0.39 to 1.60 \\
\hline Asthma medicine taken & 0.16 & 0.1 & 0.15 & 0.08 & 0.15 & 0.12 & 0.80 & 0.28 to 2.50 \\
\hline
\end{tabular}

*With the exception of the questions about asthma, all questions asked about symptoms experienced in the preceding four weeks. Responses in columns $\mathrm{A}$ to $\mathrm{F}$ are recorded as the proportions of respondents who answered "yes" to each question.

†Based on hospitality workers in premises permitting smoking (column F) relative to all unexposed workers (column E). $\mathrm{Cl}$, confidence interval. 
variation can be explained by some subjects having spent their work shifts predominantly in non-smoking parts of their workplaces, while others would have spent most of their time in areas where smoking was permitted.

The results suggesting that workers exposed to smoke during the course of their work have higher prevalences of respiratory and irritative symptoms (table 5) are suggestive, but not conclusive. There may be other lifestyle factors predisposing to such symptoms that are more prevalent in people willing to work in smoky hospitality premises than in those who work in non-smoking workplaces. These other lifestyle factors could be confounding the associations found. However, a study of workers in California bars, using similar questions, found that the reported prevalence of these symptoms decreased in workers when the law was changed to make all bars and restaurants in the state smokefree. ${ }^{16}$ This Californian study also tested respiratory function of participants and found that respiratory parameters (forced expiratory volume and forced vital capacity) improved at follow up. Results of the Californian study support an interpretation that the higher reported prevalence of symptoms found in exposed hospitality workers in this study may be a consequence of second hand smoke exposures at work. The lower rate of diagnosed asthma and use of asthma medication found in exposed hospitality workers (table 5) might be a manifestation of the so-called "healthy worker effect" ${ }^{17}$ To reduce their chances of asthmatic attacks, persons with known asthma are likely to avoid working in smoky premises.

In conclusion, this study has found convincing evidence that:

- working in hospitality premises that permit customers to smoke leads to substantially increased exposures to second hand smoke, compared with smokefree premises

- policies in hospitality premises that restrict customer smoking to certain areas substantially reduce average exposure of staff to second hand smoke, but do not eliminate such exposure.

The exposures incurred by hospitality workers in this study can be presumed to carry some risk of disease, including cancer and cardiovascular disease. Repace and colleagues ${ }^{15}$ have estimated that an average salivary cotinine concentration of $0.4 \mathrm{ng} / \mathrm{ml}$, a concentration commonly exceeded by exposed hospitality workers in this study, corresponds to an increased lifetime mortality risk of $1 / 1000$ for lung cancer, and 1/100 for heart disease. These risks fall well within the range of involuntary exposure risks commonly judged unacceptable.

\section{ACKNOWLEDGEMENTS}

We thank the following for their assistance with this study: all bar and restaurant workers, and staff from Treasury, the Department of Corrections, the Ministry of Youth Affairs, and the Ministry of Education, who took part in this study; Jan Theodorou, Penny Fairbrother, and Jenny Anderson, who administered questionnaires and collected saliva samples; Dr Paul Blanc and Dr Mark Eisner for supply of a respiratory symptom questionnaire; and the Food and Service Workers Union for assistance with recruitment. The assistance and advice of John Stribling and Matthew Allen from the Ministry of Health is particularly appreciated. This work was carried out under contract to the New Zealand Ministry of Health and is published with the permission of the ministry. Views expressed are those of the authors and do not necessarily represent the policy of the ministry.

\section{What this paper adds}

The issue of whether smoking should be permitted in hospitality premises, such as bars and restaurants, is a highly contentious one. Apart from California, few jurisdictions have been successful in implementing smoking bans in such premises. Although it might be argued that customer attendance is voluntary, for hospitality workers exposure to environmental tobacco smoke (ETS) is unavoidable. To date, data on actual work related exposures of hospitality workers to ETS have been almost non-existent, and could only be indirectly inferred from smoke measurements. This absence of data has weakened the case for provision of smokefree hospitality premises.

This study has provided the first objective data on the actual extent of exposure of hospitality workers to ETS in the workplace. It shows there are exposure reduction benefits when customer smoking is restricted to certain areas. However, employees in workplaces with limited customer smoking restrictions are still considerably more highly exposed to ETS than employees in smokefree workplaces.

\section{Authors' affiliations}

*M N Bates, J Fawcett, S Dickson, R Berezowski, N Garrett, Institute of Environmental Science and Research Ltd, PO Box 50-348, Porirua, New Zealand

*Also the School of Public Health, University of California, Berkeley, California, USA

\section{REFERENCES}

1 Kawachi I, Colditz G. Workplace exposure to passive smoking and risk of cardiovascular disease: summary of epidemiologic studies. Environ Health Persp 1999; 107:847-52

2 Lubin J. Estimating lung cancer risk with exposure to passive smoking 2 Lubin J. Estimating lung cancer risk with
Environ Health Persp 1999;107:870-84.

3 Hammond SK. Exposure of US Workers to Environmental Tobacco Smoke. Environ Health Persp 1999;107:329-40.

4 Lambert WE, Samet JM, Spengler JD. Environmental tobacco smoke concentrations in no-smoking and smoking sections of restaurants. Am J Public Health 1993;83:1339-41.

5 Etter J-F, Duc Tv, Permeger TV. Saliva cotinine levels in smokers and nonsmokers. Am J Epidem 2000;151:251-8.

6 Curvall M, Vala EK, Enzell CR, et al. Simulation and evaluation of nicotine intake during passive smoking: Cotinine measurements in body fluids of non-smokers given intravenous infusions of nicotine. Clin Pharmacol Ther 1990;47:42-9

7 Al-Delaimy W, Fraser T, Woodward A. Nicotine in hair of bar and restaurant workers. N Z Med J 2001;114:80-3.

8 Jenkins RA, Counts RW. Personal exposure to environmental tobacco smoke; salivary cotinine, airborne nicotine, and nonsmoker misclassification. J Exp Analyt Environ Epidem 1999;9:352-63.

9 Trout D, Decker J, Mueller C, et al. Exposure of casino employees to environmental tobacco smoke. J Occup Environ Med 1998;40:270-6.

10 Coultas D, Samet H, McCarthy J, et al. A personal monitoring study to assess workplace exposure to environmental tobacco smoke. Am J Public Health 1990;80:988-90.

11 Bergman TA, Johnson DL, Boatright DT, et al. Occupational exposure of non-smoking nightclub musicians to environmental tobacco smoke. Am Ind Hyg Assoc J 1996;57:746-52.

12 Siegel $M$. Involuntary smoking in the restaurant workplace. JAMA 1993;270:490-3

13 Kuusimaki L, Pfaffli P, Froshaug $M$, et al. Determination of nicotine as an indicator of environmental tobacco smoke in restaurants. Am J Ind Med 1999;1(suppl 1):152-4.

14 Maskarinec MP, Jenkins RA, Counts RW, et al. Determination of exposure to environmental tobacco smoke in restaurant and tavern workers in one US city. J Exp Analyt Environ Epidem 2000;10:36-49.

15 Repace JL, Jinot J, Bayard S, et al. Air nicotine and saliva cotinine as indicators of workplace passive smoke exposure and risk. Risk Analysis 1998; 18:71-83.

16 Eisner MD, Smith AK, Blanc PD. Bartenders' respiratory health after establishment of smoke-free bars and taverns. JAMA 1998;280:1909-14.

17 Checkoway H, Pearce N, Crawford-Brown D. Research methods in occupational epidemiology. New York: Oxford University Press, 1989 